\title{
Changes in milk production and blood metabolism of lactating dairy cows fed Saccharomyces cerevisiae culture fluid under heat stress
}

\author{
Dong-Hyun Lim¹, Man-Hye Han ${ }^{1}$ Kwang-Seok Ki ${ }^{1}$, Tae-II Kim, \\ Sung-Min Park ${ }^{1}$, Dong-Hyeon $\mathrm{Kim}^{1}$ and Younghoon $\mathrm{Kim}^{2 *}$ \\ ${ }^{1}$ Dairy Science Division, National Institute of Animal Science, Rural Development Administration, \\ Cheonan 31000, Korea \\ ${ }^{2}$ Department of Agricultural Biotechnology and Research Institute of Agriculture and Life Science, Seoul \\ National University, Seoul 08826, Korea
}

Received: Oct 2, 2021

Revised: Oct 9, 2021

Accepted: Oct 10, 2021

\section{*Corresponding author}

Younghoon Kim

Department of Agricultural

Biotechnology and Research Institute

of Agriculture and Life Science, Seoul

National University, Seoul 08826,

Korea.

Tel: +82-2-880-4808

E-mail: ykeys2584@snu.ac.kr

Copyright $@ 2021$ Korean Society of Animal Sciences and Technology.

This is an Open Access article distributed under the terms of the Creative Commons Attribution

Non-Commercial License (http:// creativecommons.org/licenses/by$\mathrm{nc} / 4.0 /$ ) which permits unrestricted non-commercial use, distribution, and reproduction in any medium, provided the original work is properly cited.

ORCID

Dong-Hyun Lim

https://orcid.org/0000-0002-8575-0198

Man-Hye Han

https://orcid.org/0000-0002-8104-4587

Kwang-Seok Ki

https://orcid.org/0000-0003-0971-1389

Tae-II Kim

https://orcid.org/0000-0003-0532-6010

Sung-Min Park

https://orcid.org/0000-0001-9534-0216

\section{Abstract}

In this study, Saccharomyces cerevisiae culture fluid (SCCF) has been added to a diet of lactating dairy cows to attempt to improve the ruminal fermentation and potentially increase the dry matter intake (DMI) and milk yield. This study was conducted to investigate the effects of SCCF on the milk yield and blood biochemistry in lactating cows during the summer. Twenty-four Holstein dairy cows were randomly assigned to one of four treatments: (1) total mixed ration (TMR-1) (Control); (2) TMR-1 supplemented with SCCF (T1); (3) TMR-2 (containing alfalfa hay) (T2); and (4) TMR-2 supplemented with SCCF (T3). SCCF (5 ml/head, 2.0×10 $\mathrm{CFU} / \mathrm{mL}$ ) was mixed with TMRs daily before feeding to dairy cows. The mean daily temperature-humidity index (THI) during this trial was $76.92 \pm 0.51$ on average and ranged from 73.04 to 81.19. For particle size distribution, TMR-2 had a lower $>19 \mathrm{~mm}$ fraction and a higher 8-19 $\mathrm{mm}$ fraction than TMR-1 $(p<0.05)$. The type of TMR did not influence the DMI, body weight (BW), milk yield and composition, or blood metabolites. The milk yield and composition were not affected by the SCCF supplementation, but somatic cell counts were reduced by feeding SCCF $(p<0.05)$. Feeding SCCF significantly increased the DMI but did not affect the milk yield of dairy cows. The NEFA concentration was slightly decreased compared to that in the control and T2 groups without SCCF. Feeding a yeast culture of $S$. cerevisiae may improve the feed intake, milk quality and energy balance of dairy cows under heat stress.

Keywords: Saccharomyces cerevisiae, Milk production, Blood metabolism, Dairy cow, Heat stress

\section{INTRODUCTION}

Milk production by dairy cows has increased by $41 \%(2,802 \mathrm{~kg} / \mathrm{head})$ in milk yield and $0.12 \%(120.04$ $\mathrm{kg} / \mathrm{head}$ ) in milk fat from 2,000 to 2,020 in Korea [1]. With these improvements and selection, dairy 
Dong-Hyeon Kim

https://orcid.org/0000-0003-0756-8419

Younghoon Kim

https://orcid.org/0000-0001-6769-0657

Competing interests

No potential conflict of interest relevant to

this article was reported.

Funding sources

This study was carried out with the support

of "Cooperative Research Program for

Agricultural Science and Technology

Development (Project title: Study on

developing behavior and reproductive

indices for evaluation of lactating cow's heat

stress; Project No: PJ014295) of the Rural

Development Administration of the Korea.

Acknowledgements

Not applicable.

Availability of data and material Upon reasonable request, the datasets of this study can be available from the corresponding author.

Authors' contributions

Conceptualization: Lim DH, Han MH, Ki KS, Kim TI, Park SM, Kim DH, Kim Y.

Data curation: Lim DH, Han MH, Ki KS, Kim TI, Park SM, Kim DH, Kim Y.

Formal analysis: Lim DH, Han MH, Ki KS, Kim TI, Park SM, Kim DH, Kim Y.

Methodology: Lim DH, Han MH, Ki KS, Kim TI, Park SM, Kim DH.

Software: Lim DH, Han MH, Ki KS, Kim TI, Park SM, Kim DH.

Validation: Lim DH, Han MH, Ki KS, Kim TI, Park SM, Kim DH, Kim Y.

Investigation: Lim DH, Han MH, Ki KS, Kim TI, Park SM, Kim DH, Kim Y.

Writing - original draft: Lim DH, Han MH, Ki KS, Kim TI, Park SM, Kim DH, Kim Y.

Writing - review \& editing: Lim DH, Han MH, Ki KS, Kim TI, Park SM, Kim DH, Kim Y.

Ethics approval and consent to participate All dairy cows and the experimental protocol in this experiment were approved by the Institutional Animal Care and Use Committee (IACUC, study approval number: 20191519) at the National Institute of Animal Science (NIAS, Jeonju, Korea). cows are more sensitive to heat stress, which directly or indirectly influences the normal physiology, metabolism, and hormonal and immune systems [2]. Heat stress also causes economic losses according to negative effects on the milk production, milk composition, reproductive efficiency, and udder health $[2,3]$. Thus, environmental and nutritional methods to alleviate heat stress have been studied to improve the lactation performance of dairy cows.

In particular, feed additives, including yeast supplements such as Saccharomyces cerevisiae, are widely used to improve the lactation performance and health in dairy cows [4,5]. Many studies have reported that feeding $S$. cerevisiae positively influences the dry matter intake (DMI), rumen $\mathrm{pH}$, nutrient digestibility, immune function and milk quality of dairy cows [5-7]. Because of its effects on the rumen fermentation and nutrient digestion, some authors have suggested that feeding yeast products may be most beneficial to dairy cows under heat stress [8-12]. Arambel and Kent [8] suggested that yeast products might be more effective under heat stress than under normal conditions. Schingoethe et al. [9] reported a significant improvement in feed efficiency when midlactating dairy cows were supplemented with $S$. cerevisiae during summer months. S. cerevisiae culture contains fermentation substrates, bacterial proteins, yeast metabolites, yeast cell walls, and other beneficial substances, and it can balance the interstinal flora, improve immunity, relieve stress, and improve productivity [10].

Recently, several agricultural technology centers in Korea have supplied microbial cultures such as Lactobacillus plantarum, Bacillus subtilis, and S. cerevisiae, which are known to effectively improve the feed efficiency, productivity and environment of livestock. However, research on the method or effectiveness of feeding $S$. cerevisiae culture to dairy cows is limited. There is also limited understanding of how S. cerevisiae culture affects the lactation performance of heat-stressed dairy cows associated with blood metabolism. Therefore, we hypothesized that $S$. cerevisiae culture would improve the milk productivity and blood metabolism of dairy cows exposed to heat stress if feeding $S$. cerevisiae could increase the DMI of dairy cows under such conditions. To address this hypothesis, the effects of the $S$. cerevisiae culture addition in different total mixed rations (TMRs) on DMI, milk production and quality, and energy status in dairy cows during heat stress were evaluated.

\section{MATERIALS AND METHODS}

\section{Animals, diets, and experimental design}

All dairy cows and the experimental protocol in this experiment were approved by the Institutional Animal Care and Use Committee (IACUC, study approval number: 20191519) at the National Institute of Animal Science (NIAS, Jeonju, Korea). The experiment was conducted at the Department of Animal Resources Development, NIAS (Cheonan, Korea). Twenty-four Holstein dairy cows were allocated into 4 groups based on day in milk (DIM) $(187.3 \pm 41.9$; mean \pm standard deviation), parity $(1.75 \pm 0.19)$, milk yield $(31.21 \pm 1.05 \mathrm{~kg} / \mathrm{d})$, and body weight $(\mathrm{BW})$ $678 \pm 10.67 \mathrm{~kg}$. The cows were randomly assigned within blocks to one of four dietary treatments: (Control) TMR-1; (T1) TMR-1 supplemented with $S$. cerevisiae culture fluid (SCCF, $5 \mathrm{~mL} / \mathrm{head}$ ); (T2) TMR-2; and (T3) TMR-2 supplemented with SCCF (Table 1). TMR-1 was mixed with domestic forages such as corn silage, rice straw silage, and whole-crop barley silage. TMR-2 was mixed by adding alfalfa hay, which has mainly been used in dairy farms, in addition to domestic forages of TMR-1. SCCF (S. cerevisiae, ca. 2.0×107 CFU/mL, AAH180004, Anseong 40-18-83100), which is a fully fermented yeast culture containing fermentation metabolites, residual yeast cells, and growth media, was provided by the Agricultural Technology Center (Anseong, Korea). The SCCF supplementations were mixed with TMRs daily at the time of feeding to dairy cows. 
Table 1. Experimental design and composition of TMRs in the experiment

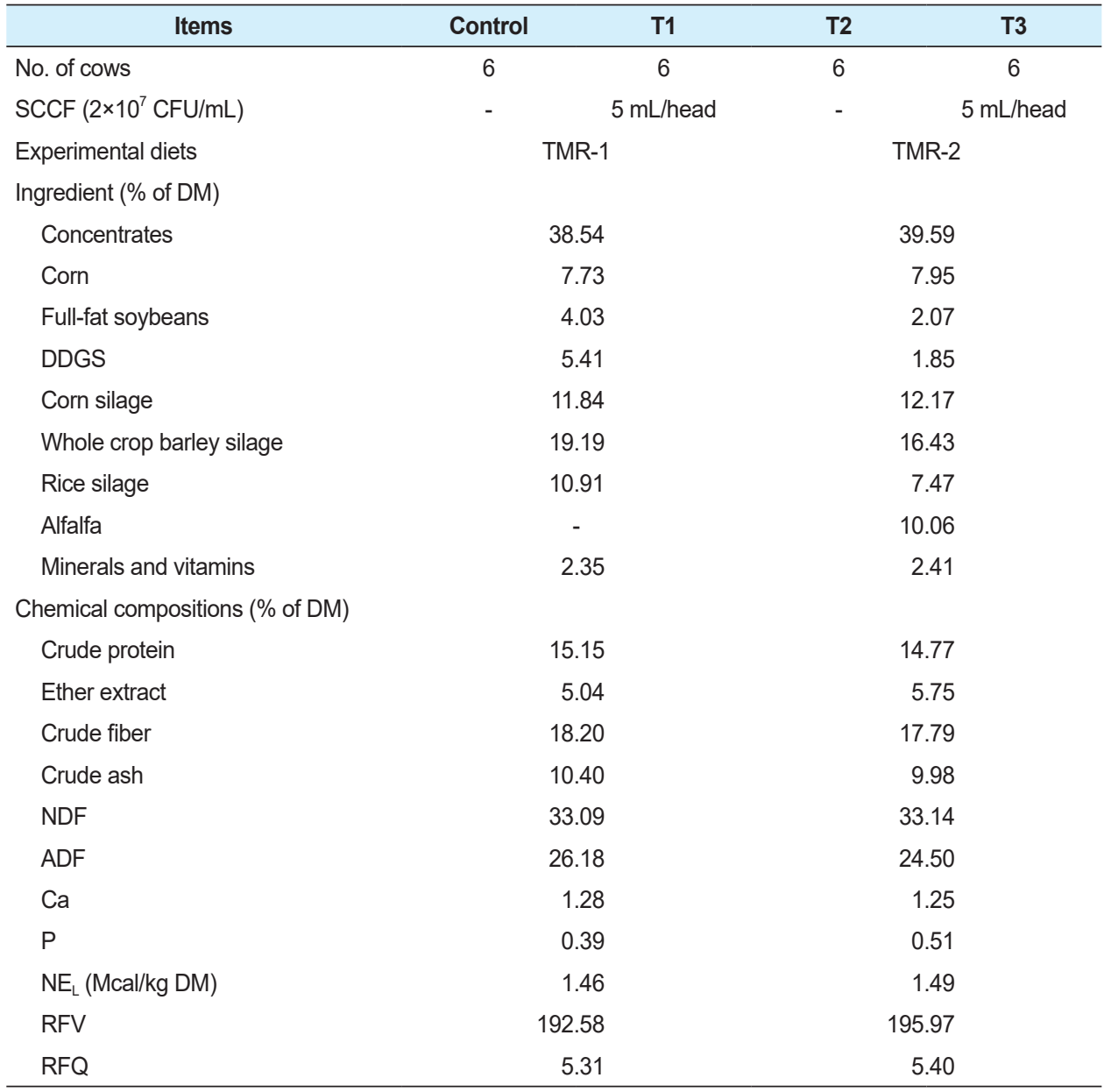

TMR, total mixed ration; SCCF, Saccharomyces cerevisiae culture fluid (Agriculture Technology Center, Anseong, Korea); DM, dry matter; DDGS, dried distiller's grains with solubles; NDF, neutral detergent fiber; $A D F$, acid detergent fiber; $\mathrm{NE}_{\mathrm{L}}$, net energy for lactation; RFV, relative feed value; RFQ, relative feed quality

TMR-1 and TMR-2 were formulated to satisfy or exceed the nutrient requirements [13] for lactating Holstein dairy cows (DMI $22.0 \mathrm{~kg} / \mathrm{d}$, net energy for lactation $\left[\mathrm{NE}_{\mathrm{L}}\right] 32.5 \mathrm{Mcal} / \mathrm{d}$ ). The ingredient and nutrient contents of the feed components are presented in Table 1.

Cows were housed in a loose barn and fed the TMR daily at 09:00 with free access to drinking water. Feed was offered ad libitum to yield $10 \%$ residues. The barn contained fans over feeding alleys every $5 \mathrm{~m}$, and the fans were operated once the ambient temperature reached $25^{\circ} \mathrm{C}$. The experiment commenced from July 12 to August 8, which is the typical hot season in Cheonan, Korea. The feeding trial was composed of a 2-week adaptation period and a 2-week experimental period.

\section{Sampling and measurement of milk composition}

To measure the environmental conditions inside the barn, temperature and relative humidity $(\mathrm{RH})$ were recorded by a thermohygrometer (Model 174H, Testo, West Chester, PA, USA) with an accuracy of $\pm 0.5^{\circ} \mathrm{C}$ and $\pm 3 \% \mathrm{RH}$. A thermohygrometer was set to record every hour per day and placed at a height of $2 \mathrm{~m}$ from the feeding area. The temperature-humidity index (THI) was calculated as THI $=(0.8 \times \mathrm{C})+[\mathrm{RH} \% \times(\mathrm{C}-14.4)]+46.4$ according to Mader et al. [14]. For each $24 \mathrm{~h}$ period, the average daily minimum, mean and maximum temperatures and $\mathrm{RH}$ were determined using the hourly recorded data, and the minimum, mean and maximum THIs were 
calculated (Fig. 1 and Table 3). Feed offered and residues were weighed daily to determine the DMI throughout the experiment. Representative samples of individual dietary ingredients and TMR were collected weekly and stored at $-20^{\circ} \mathrm{C}$ until analyses. All samples were analyzed by AOAC [15] for concentrations of dry matter, crude protein, ether extract, crude fiber, and crude ash and by Van Soest et al. [16] for concentrations of neutral detergent fiber (NDF) and acid detergent fiber (ADF). Particle size distributions of TMR-1 and TMR-2 were measured by sieving using the Penn State Particle Separator [17]. The sum of the DM retained on the top $(19 \mathrm{~mm})$ and middle sieves $(8 \mathrm{~mm}$ ) was assumed to be equal to the physical effectiveness factor (pef) of feeds.

Cows were milked 2 times daily at 06:00 and 17:00 h, and individual milk production was recorded daily using a DeLaval's Alpro Herd management system (DeLaval international, Tumba, Sweden) with a double-eight herringbone parlor. Individual milk samples were collected from consecutive morning and afternoon milking on the seventh day of each week from each cow. The milk samples were analyzed to obtain the somatic cell count (SCC), fat, protein, lactose, total solids, and milk urea nitrogen (MUN) concentrations using a CombiScope FTIR (Delta Instruments, Drachten, Netherlands).

\section{Analysis of blood metabolites}

All cows were sampled for blood on the last day of the study. Blood samples of each cow were taken through the jugular vein with a syringe before feeding the cows. The collected blood samples were transferred into vacutainer tubes (BD Vacutainer, Becton Dickinson, Frankin Lakes, NJ, USA) and centrifuged at $1,000 \times \mathrm{g}$ for $15 \mathrm{~min}$ at $4{ }^{\circ} \mathrm{C}$. The serum samples were immediately frozen at $-20^{\circ} \mathrm{C}$ and later analyzed for aspartate aminotransferase (AST), alanine aminotransferase (ALT), glucose, triglyceride, cholesterol, nonessential fatty acid (NEFA), blood urea nitrogen (BUN), and creatinine concentrations. Serum samples were used to analyze biochemistry (Wako Chemicals, Neuss, Germany) using a blood autoanalyzer (Hitachi 7180, Hitachi, Tokyo, Japan).

\section{Statistical analysis}

Statistical analysis was conducted using the Statistical Analysis System (SAS) Enterprise Guide 7.1 (SAS Institute, Cary, NC, USA). The particle size distribution was analyzed to determine the effects of the experimental TMRs with one-way analysis of variance (ANOVA). The DMI, BW

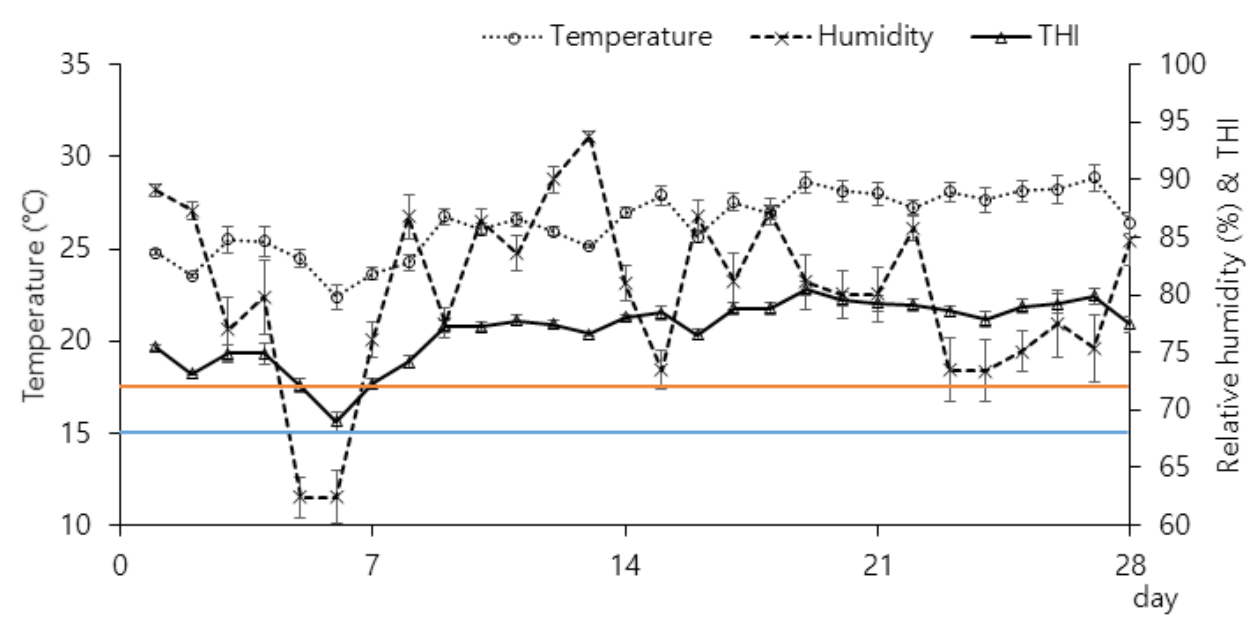

Fig. 1. Daily mean temperature, relative humidity, and temperature-humidity index (THI) during the study. The dashed lines represent two THI threshold values: 68 THI (blue color) and 72 THI (orange color). 
gain, milk yield, milk composition, and blood metabolite data were analyzed by two-way ANOVA using the general linear model procedure to determine the main effects, treatments (with or without SCCF) and TMR (no vs. mixing the alfalfa hay), and their interaction (Treatment $\times$ TMR). If there were differences, we continued with the Duncan multiple range test. Differences with $p<0.05$ were declared significant. Duncan's multiple range test was used to evaluate the significant differences.

\section{RESULTS AND DISCUSSION}

\section{Environmental temperature, humidity, and temperature-humidity index}

The average mean daily temperature $\left({ }^{\circ} \mathrm{C}\right)$ and $\mathrm{RH}(\%)$ during the entire experiment were 26.40 $\pm 0.32{ }^{\circ} \mathrm{C}$ and $80.32 \pm 1.39 \%$, respectively (Fig. 1 ). The average mean daily THI (76.92 \pm 0.51$)$ in the barn housing cows over all days exceeded 68 , which characterizes exposure to heat stress for lactating dairy cows [18]. The daily THI variation was $8.14 \pm 0.54$ on average and ranged from 73.04 to 81.19 (Table 2).

A THI value of 72 is a critical threshold value, above which the productive properties of the cow begin to change and a drop in productivity is noted [19]. Recent studies state that THI 68 is the lower limit for the occurrence of heat stress [18]. Carter et al. [18] noted that high-yield dairy cows experienced heat stress when average daily THI $>68$ or minimum daily THI $>65$. From previous studies, environmental conditions over all days caused heat stress for lactating dairy cows.

\section{Particle size distribution}

Table 3 shows that TMR-2 had a lower proportion retained on the top screen $(>19 \mathrm{~mm})$ and a higher proportion retained on the middle screen $(8-19 \mathrm{~mm})$ than TMR-1 $(p<0.05)$. The particle size distribution of TMR-2, which replaced some of the long forage such as whole crop barle (WCB) and rice silage with alfalfa hay, resulted in lower physically effective neutral detergent fiber (peNDF)19.0 and peNDF8.0 than those in TMR-1 $(p<0.05)$.

The particle size distribution of TMRs in this study did not satisfy the recommendation guidelines suggested by Heinrichs and Kononoff [20]: 2\%-8\% long particles (> $19 \mathrm{~mm}$ ), 30\%-50\%

Table 2. Daily minimum, mean, and maximum temperature, relative humidity, and temperature-humidity index (THI) during this experiment

\begin{tabular}{lccc}
\hline \multicolumn{1}{c}{ Items } & Temperature $\left({ }^{\circ} \mathrm{C}\right)$ & Relative humidity (\%) & THI \\
\hline Average daily & & & \\
Mean & $26.40 \pm 0.32$ & $80.32 \pm 1.39$ & $76.92 \pm 0.51$ \\
Minimum & $23.20 \pm 0.36$ & $64.79 \pm 2.14$ & $73.04 \pm 0.63$ \\
Maximum & $30.36 \pm 0.51$ & $93.86 \pm 0.66$ & $81.19 \pm 0.62$ \\
\hline
\end{tabular}

Table 3. Particle size distribution and peNDF of TMRs determined by the Penn state particle separator

\begin{tabular}{lcccc}
\hline \multicolumn{1}{c}{ Items } & TMR-1 & TMR-2 & SEM & $p$-value \\
\hline Particle fractions on sieve $(\%$ [DM basis]) & $15.11^{\mathrm{a}}$ & $11.78^{\mathrm{b}}$ & 0.53 & $<0.001$ \\
Top $(19 \mathrm{~mm})$ & $23.79^{\mathrm{b}}$ & $25.52^{\mathrm{a}}$ & 0.27 & $<0.001$ \\
Middle $(8 \mathrm{~mm})$ & 61.11 & 62.70 & 0.47 & 0.091 \\
Bottom & $5.39^{\mathrm{a}}$ & $3.90^{\mathrm{b}}$ & 0.20 & $<0.001$ \\
$\operatorname{peNDF}_{19.0}(\%)$ & $13.91^{\mathrm{a}}$ & $12.36^{\mathrm{b}}$ & 0.20 & $<0.001$ \\
$\operatorname{peNDF}_{8.0}(\%)$ & & & \\
\hline
\end{tabular}

a,benotes comparison made within rows $(p<0.05)$.

peNDF, physical effective neutral detergent fiber; TMR, total mixed ration; DM, dry matter. 
medium and short particles $(8-19 \mathrm{~mm})$, and no more than $20 \%$ fine particles $(<8 \mathrm{~mm})$. A particle fraction $>19 \mathrm{~mm}$ and peNDF8.0 were good parameters for monitoring the TMR physical form indicator to improve the chewing activity and rumen $\mathrm{pH}$ and prevent sorting [21]. In this study, beneficial physical effects were not observed for TMR with added alfalfa hay because TMR-2 had fewer particles $>19 \mathrm{~mm}$ but more particles $<8 \mathrm{~mm}$ than TMR-1.

\section{Dry matter intake, body weight, milk yield and composition}

The intake of DM in all treatments did not differ by the type of TMR (TMR-1 and TMR-2) (Table 4). This result is not consistent with Fischer et al. [22], who observed that the DMI was higher for those fed hay and TMR containing short instead of long silage. Meanwhile, the DMI was $2.7 \mathrm{~kg} / \mathrm{d}$ higher for T1- and T3-supplemented S. cerevisiae than for the control and T2 cows ( $p$ $<0.05)$. Similar tendencies were observed in some studies: the DMI in dairy cows was affected by S. cerevisiae supplementation during early lactation [23] or mid-lactation during the summer [11]. Heat-stressed cows reduce the feed intake, rumination and saliva production. It may act as a risk factor to make the rumen function inappropriate [11]. S. cerevisiae can alter the ruminal microbial fermentation by stimulating the activity of fiber-digesting bacteria and increasing fiber digestion [6]. From the present study, feeding S. cerevisiae may mitigate the negative effect of heat stress on the DMI of dairy cows.

Milk yield were not affected among the treatments. However, some studies reported that the milk yield increased with increasing levels of $S$. cerevisiae under normal conditions [11]. Additionally, when heat-stressed dairy cows were fed yeasts and yeast cultures, milk production increased by $1-2 \mathrm{~kg} / \mathrm{d}[23,24]$. In this study, the reduction of milk yield numerically was lower in T1 and T3 (-1.16 and $-1.89 \mathrm{~kg} / \mathrm{d}$, respectively) with supplemented S. cerevisiae than in control and T2 (-2.69 and $-2.23 \mathrm{~kg} / \mathrm{d}$, respectively) with prolonged exposure to heat stress compared with the beginning of this trial (Fig. 2). Dairy cows exposed to heat stress exhibited decreased milk yield due to the high metabolic heat production with ruminal fermentation [2,3]. However, according to Callaway and Martin [6], the beneficial effects of S. cerevisiae supplementation on milk production resulted from the stabilized condition of rumen fermentation.

The feeding treatment of $S$. cerevisiae had no impact on the concentration of fat, protein, and lactose. These results are consistent with Arambel and Kent [8], who found that S. cerevisiae supplementation had no positive effect on the milk composition of dairy cows. Specifically, no

Table 4. Effect of the Saccharomyces cerevisiae supplementation on the dry matter intake, milk production and composition in dairy cows that were fed different TMRs during heat stress

\begin{tabular}{|c|c|c|c|c|c|c|c|c|}
\hline \multirow{2}{*}{ Items } & \multicolumn{2}{|c|}{ TMR-1 } & \multicolumn{2}{|c|}{ TMR-2 } & \multirow{2}{*}{ SEM } & \multicolumn{3}{|c|}{$p$-value } \\
\hline & Control & T1 & T2 & T3 & & Treat & TMR & Treat $\times$ TMR \\
\hline $\mathrm{DMl}(\mathrm{kg} / \mathrm{d})$ & $18.69^{b}$ & $21.13^{a}$ & $18.71^{b}$ & $21.67^{a}$ & 0.20 & $<0.001$ & 0.354 & 0.401 \\
\hline BW gain $(\mathrm{kg})$ & -9.42 & -0.08 & 2.42 & -11.25 & 4.07 & 0.798 & 0.969 & 0.184 \\
\hline Milk yield $(\mathrm{kg} / \mathrm{d})$ & 28.85 & 29.89 & 28.30 & 29.85 & 0.43 & 0.095 & 0.215 & 0.286 \\
\hline Fat (\%) & 3.54 & 3.69 & 3.56 & 3.70 & 0.07 & 0.308 & 0.887 & 0.991 \\
\hline Protein (\%) & 3.06 & 3.02 & 2.99 & 3.08 & 0.03 & 0.720 & 0.799 & 0.310 \\
\hline Lactose (\%) & 4.74 & 4.70 & 4.76 & 4.75 & 0.02 & 0.549 & 0.443 & 0.623 \\
\hline Total solids (\%) & $11.14^{b}$ & $12.16^{a}$ & $10.88^{b}$ & $12.29^{a}$ & 0.16 & $<0.001$ & 0.742 & 0.513 \\
\hline $\operatorname{SCC}\left(\times 10^{3} / \mathrm{mL}\right)$ & $202.0^{\mathrm{a}}$ & $114.3^{b}$ & $237.8^{\mathrm{a}}$ & $99.8^{b}$ & 81.73 & 0.002 & 0.476 & 0.875 \\
\hline MUN (mg/dL) & $14.48^{\mathrm{a}}$ & $7.25^{b}$ & $14.12^{\mathrm{a}}$ & $6.85^{\mathrm{b}}$ & 0.42 & $<0.001$ & 0.415 & 0.966 \\
\hline
\end{tabular}

Treat, supplementation or not with $\mathrm{S}$. cerevisiae culture fluid $\left(5 \mathrm{~mL} / \mathrm{head}, 2 \times 10^{7} \mathrm{CFU} / \mathrm{mL}\right)$.

a,b Denotes comparison made within rows $(p<0.05)$.

TMR, total mixed ration; DMI, dry matter intake; BW, body weight; SCC, somatic cell count; MUN , milk urea nitrogen. 


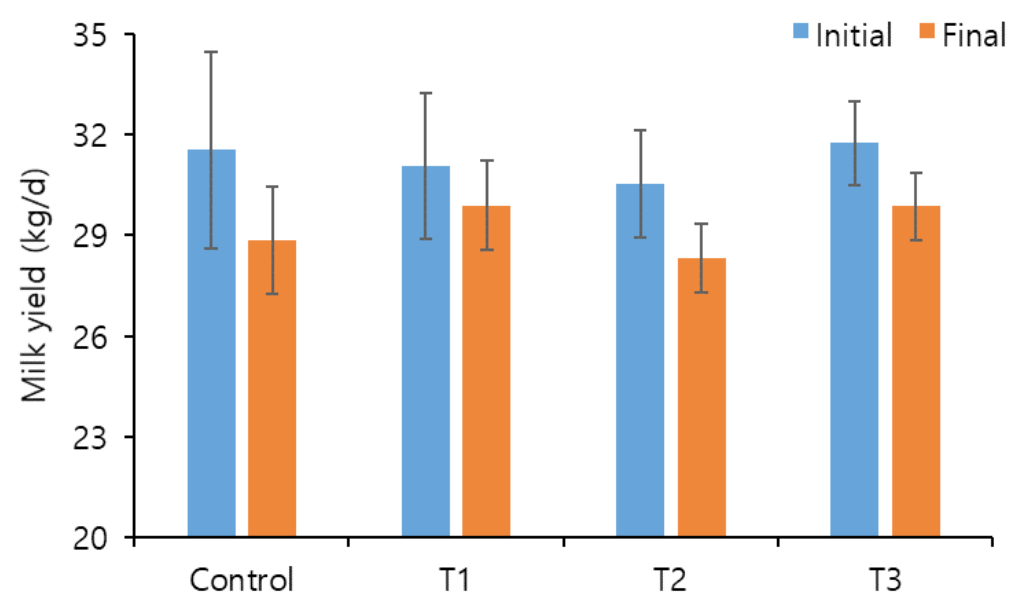

Fig. 2. Milk production in dairy cows that were fed different TMRs before and after feeding Saccharomyces cerevisiae culture fluid (SCCF) supplementation during heat stress. TMR, total mixed ration.

changes in percentage of milk fat and protein appeared in lactating dairy cows under heat stress $[9,11]$. However, the total solids in milk were higher in dairy cows that were fed SCCF than in those not fed SCCF $(p<0.05)$.

SCC is a commonly used index of milk quality and a defense component of mammary glands against disease or intramammary infections [25]. The SCC in the present study was reduced by feeding $S$. cerevisiae $(p<0.05)$. Similarly, some studies reported that yeast product supplementation improved the mammary gland health in lactating dairy cows and reduced the incidence of mastitis $[4,7]$. These results are not fully explained but may be due to immunomodulation with antioxidant and anti-inflammatory effects of yeast product supplementation [26]. Although it is difficult to clearly explain the relationship between $S$. cerevisiae supplementation and SCC in milk from this study, yeast feed addition appears to help alleviate the increase in SCC during heat stress in a previous study.

Feeding SCCF decreased the MUN concentration in milk $(p<0.05)$, which corroborates previous studies [11] indicating that $S$. cerevisiae supplements reduced MUN during natural heat stress. Other studies observed that heat stress increased MUNs, and feeding SCCFs had no detectable effects on MUNs [12]. Heat-stressed cows mobilize skeletal muscle to provide amino acids to produce acute-phase proteins [27] and glucose [28]. The difference in the results of previous studies and this study may be due to different stages of lactation, feeding strategy (type of forage fed, feeding strategy, and forage-to-concentrate ratio [5,29]), and heat stress severity [12].

\section{Serum metabolites from blood samples}

The NEFA concentrations were slightly different between treatments with or without SCCF supplementation and, according to control, BUN was affected on the TMR groups either with alfalfa hay or not $(p<0.05$; Table 5). The other metabolic indices, including AST, ALT, glucose, triglyceride, cholesterol, and creatinine, were not affected by the SCCF supplementation or experimental TMRs.

Some studies observed that the blood parameters were not affected by the $S$. cerevisiae treatment $[12,29]$. However, other studies reported that $S$. cerevisiae supplementation favorably influenced the energy metabolic status and might have a liver-protecting effect on high-yield cows [30,31].

Cows in a state of negative energy balance are biochemically characterized by elevations in blood 
Table 5. Effect of the Saccharomyces cerevisiae supplementation on blood metabolites in dairy cows that were fed different TMRs during heat stress

\begin{tabular}{|c|c|c|c|c|c|c|c|c|}
\hline \multirow{2}{*}{ Items } & \multicolumn{2}{|c|}{ TMR-1 } & \multicolumn{2}{|c|}{ TMR-2 } & \multirow{2}{*}{ SEM } & \multicolumn{3}{|c|}{$p$-value } \\
\hline & No & SCCF & No & SCCF & & Treat & TMR & Treat $\times$ TMR \\
\hline AST (GOT) (IU/L) & 78.00 & 83.00 & 78.08 & 69.08 & 4.41 & 0.947 & 0.453 & 0.448 \\
\hline ALT (GPT) (IU/L) & 22.44 & 22.11 & 24.58 & 23.33 & 0.89 & 0.700 & 0.366 & 0.804 \\
\hline Glucose (mg/dL) & 48.28 & 45.33 & 48.08 & 49.00 & 1.25 & 0.583 & 0.505 & 0.458 \\
\hline Triglyceride (mg/dL) & 8.56 & 7.17 & 7.25 & 7.92 & 0.26 & 0.177 & 0.600 & 0.056 \\
\hline Cholesterol (mg/dL) & 203.11 & 194.83 & 205.33 & 189.92 & 5.82 & 0.351 & 0.912 & 0.769 \\
\hline $\mathrm{NEFA}(\mathrm{mg} / \mathrm{dL})$ & $78.89^{a}$ & $40.67^{\mathrm{ab}}$ & $70.83^{a}$ & $23.17^{\mathrm{b}}$ & 7.25 & 0.003 & 0.363 & 0.736 \\
\hline BUN (mg/dL) & $16.89^{a}$ & $17.39^{\mathrm{a}}$ & $13.86^{\mathrm{b}}$ & $14.51^{\mathrm{b}}$ & 0.41 & 0.451 & $<0.001$ & 0.924 \\
\hline Creatinine & 1.16 & 1.21 & 1.08 & 1.18 & 0.02 & 0.070 & 0.168 & 0.574 \\
\hline
\end{tabular}

Treat, supplementation or not with $S$. cerevisiae culture fluid $\left(5 \mathrm{~mL} / \mathrm{head}, 2 \times 10^{7} \mathrm{CFU} / \mathrm{mL}\right)$.

${ }^{a, b}$ Denotes comparison made within rows $(p<0.05)$.

TMR, total mixed ration; SCCF, Saccharomyces cerevisiae culture fluid; AST, aminotransferase; ALT, alanine aminotransferase; GOT, glutamic oxaloacetic transaminase; GPT, glutamlc pyruvic transamlnase; NEFA, nonessential fatty acid; BUN, blood urea nitrogen.

biochemical parameters such as $\beta$-hydroxybutyrate (BHB) and NEFA and reductions in glucose concentrations [32]. In the current study, a lower NEFA concentration was observed in dairy cows fed SCCF $(p<0.05)$. This result is consistent with the results reported by Kumprechtova et al. [30] that the NEFA level was lower in early lactation dairy cows fed S. cerevisiae supplementation. Their study explained that lower NEFA levels might be considered a sign of reduced lipomobilization processes and hepatic ketogenesis. Dairy cows that were offered TMR with alfalfa had lower BUN concentrations, probably as a result of the lower total $\mathrm{N}$ and energy consumption than those of TMR with whole-crop barley.

The effects of SCCF on the lactation performance and blood metabolism of dairy cows remain inconsistent among previous studies. However, little research has been conducted on the effects of S. cerevisiae dietary supplementation on heat-stressed dairy cows, so further study relating to this issue is required.

\section{CONCLUSION}

In the present study, SCCF supplementation was fed to mid-lactating dairy cows during heat stress under the conditions with different ingredients of TMR to improve the milk productivity and blood metabolism. The findings of this study reveal that S. cerevisiae alleviated the reduction in DMI and the increase in SCC in heat-stressed dairy cows but did not affect the milk composition. Feeding S. cerevisiae contributed to a decrease in NEFA concentration, which reflects the energy metabolism, but did not affect the other blood parameters. Thus, SCCF supplementation can increase the DMI and improve the milk quality.

\section{REFERENCES}

1. MAFRA [Ministry of Agriculture Food and Rural Affairs], Korea Dairy Committee. 2021 Dairy statistics yearbook. Sejong: Korea Dairy Committee; 2021.

2. West JW. Effects of heat-stress on production in dairy cattle. J Dairy Sci. 2003;86:2131-44. https://doi.org/10.3168/jds.S0022-0302(03)73803-X

3. Liu J, Li L, Chen X, Lu Y, Wang D. Effects of heat stress on body temperature, milk production, and reproduction in dairy cows: a novel idea for monitoring and evaluation of heat stress 
— a review. Asian-Australas J Anim Sci. 2019;32:1332-9. https://doi.org/10.5713/ajas.18.0743

4. Nocek JE, Holt MG, Oppy J. Effects of supplementation with yeast culture and enzymatically hydrolyzed yeast on performance of early lactation dairy cattle. J Dairy Sci. 2011;94:4046-56. https://doi.org/10.3168/jds.2011-4277

5. Yalçın S, Yalçın S, Can P, Gürdal AO, Bağcı C, Eltan Ö. The nutritive value of live yeast culture (Saccharomyces cerevisiae) and its effect on milk yield, milk composition and some blood parameters of dairy cows. Asian-Australas J Anim Sci. 2011;24:1377-85. https://doi.org/10.5713/ ajas.2011.11060

6. Callaway ES, Martin SA. Effects of a Saccharomyces cerevisiae culture on ruminal bacteria that utilize lactate and digest cellulose.J Dairy Sci. 1997;80:2035-44. https://doi.org/10.3168/ jds.S0022-0302(97)76148-4

7. Vailati-Riboni M, Coleman DN, Lopreiato V, Alharthi A, Bucktrout RE, Abdel-Hamied E, et al. Feeding a Saccharomyces cerevisiae fermentation product improves udder health and immune response to a Streptococcus uberis mastitis challenge in mid-lactation dairy cows. J Anim Sci Biotechnol. 2021;12:62. https://doi.org/10.1186/s40104-021-00560-8

8. Arambel MJ, Kent BA. Effect of yeast culture on nutrient digestibility and milk yield response in early- to midlactation dairy cows. J Dairy Sci. 1990;73:1560-3. https://doi.org/10.3168/jds. S0022-0302(90)78825-X

9. Schingoethe DJ, Linke KN, Kalscheur KF, Hippen AR, Rennich DR, Yoon I. Feed efficiency of mid-lactation dairy cows fed yeast culture during summer. J Dairy Sci. 2004;87:4178-81. https://doi.org/10.3168/jds.S0022-0302(04)73561-4

10. Bruno RGS, Rutigliano HM, Cerri RL, Robinson PH, Santos JEP. Effect of feeding Saccharomyces cerevisiae on performance of dairy cows during summer heat stress. Anim Feed Sci Technol. 2009;150:175-86. https://doi.org/10.1016/j.anifeedsci.2008.09.001

11. Zhu W, Zhang BX, Yao KY, Yoon I, Chung YH, Wang JK, et al. Effects of supplemental levels of Saccharomyces cerevisiae fermentation product on lactation performance in dairy cows under heat stress. Asian-Australas J Anim Sci. 2016;29:801-6. https://doi.org/10.5713/ ajas. 15.0440

12. Al-Qaisi M, Horst EA, Mayorga EJ, Goetz BM, Abeyta MA, Yoon I, et al. Effects of a Saccharomyces cerevisiae fermentation product on heat-stressed dairy cows. J Dairy Sci. 2020;103:9634-45. https://doi.org/10.3168/jds.2020-18721

13. National Research Council. Nutrient requirements of dairy cattle. 7th rev. ed. Washington, DC: The National Academies Press; 2001. p. 405.

14. Mader TL, Davis MS, Brown-Brandl T. Environmental factors influencing heat stress in feedlot cattle. J Anim Sci. 2006;84:712-9. https://doi.org/10.2527/2006.843712x

15. AOAC [Association of Official Analytical Chemists] International. Official methods of analysis of AOAC International. 16th ed. Washington, DC: AOAC International; 1995.

16. Van Soest PJ, Robertson JB, Lewis BA. Methods for dietary fiber, neutral detergent fiber, and nonstarch polysaccharides in relation to animal nutrition.J Dairy Sci. 1991;74:3583-97. https:// doi.org/10.3168/jds.S0022-0302(91)78551-2

17. Lammers BP, Buckmaster DR, Heinrichs AJ. A simple method for the analysis of particle sizes of forage and total mixed rations.J Dairy Sci. 1996;79:922-8. https://doi.org/10.3168/jds. S0022-0302(96)76442-1

18. Carter BH, Friend TH, Sawyer JA, Garey SM, Alexander MB, Carter MJ, et al. Effect of feed-bunk sprinklers on attendance at unshaded feed bunks in drylot dairies. Prof Anim Sci. 2011;27:127-32. https://doi.org/10.15232/S1080-7446(15)30459-9

19. Smith DL, Smith T, Rude BJ, Ward SH. Short communication: comparison of the effects of 
heat stress on milk and component yields and somatic cell score in Holstein and Jersey cows. J Dairy Sci. 2013;96:3028-33. https://doi.org/10.3168/jds.2012-5737

20. Heinrichs AJ, Kononoff PJ. Evaluating particle size of forages and TMRs using the new Penn State Forage Particle Separator. Technical Bulletin, College of Agriculture Science, Cooperative Extension. 2002. DAS 02-42.

21. Yang WZ, Beauchemin KA. Altering physically effective fiber intake through forage proportion and particle length: chewing and ruminal pH. J Dairy Sci. 2007;90:2826-38. https://doi. org/10.3168/jds.2007-0032

22. Fischer JM, Buchanan-Smith JG, Campbell C, Grieve DG, Allen OB. Effects of forage particle size and long hay for cows fed total mixed rations based on alfalfa and corn. J Dairy Sci. 1994;77:217-29. https://doi.org/10.3168/jds.S0022-0302(94)76944-7

23. Robinson PH, Garrett JE. Effect of yeast culture (Saccharomyces cerevisiae) on adaptation of cows to postpartum diets and on lactational performance. J Anim Sci. 1999;77:988-99. https:// doi.org/10.2527/1999.774988x

24. Shaver RD, Garrett JE, Hartnell G, Coppock C. Effect of dietary yeast culture on milk yield, composition, and component yields at commercial dairies. Prof Anim Sci. 1997;13:204-7. https://doi.org/10.15232/S1080-7446(15)31885-4

25. Aung M, Ohtsuka H, Izumi K. Effect of yeast cell wall supplementation on production performances and blood biochemical indices of dairy cows in different lactation periods. Vet World. 2019;12:796-801. https://doi.org/10.14202/vetworld.2019.796-801

26. Broadway PR, Carroll JA, Sanchez NCB. Live yeast and yeast cell wall supplements enhance immune function and performance in food-producing livestock: a review. Microorganisms. 2015;3:417-27. https://doi.org/10.3390/microorganisms3030417

27. Johnson RW. Fueling the immune response: What's the cost? In: Patience JF, editor. Feed Efficiency in swine. Wageningen: Wageningen Academic Publishers; 2012. p. 211-23.

28. Baumgard LH, Rhoads RP. Jr Effects of heat stress on postabsorptive metabolism and energentics. Annu Rev Anim Biosci. 2013;1:311-37. http://doi.org/10.1146/annurev-animal-031412-103644

29. Piva G, Belladonna S, Fusconi G, Sicbaldi F. Effects of yeast on dairy cow performance, ruminal fermentation, blood components, and milk manufacturing properties. J Dairy Sci. 1993;76:2717-22. https://doi.org/10.3168/jds.S0022-0302(93)77608-0

30. Kumprechtová D, Illek J, Julien C, Homolka P, Jančík F, Auclair E. Effect of live yeast (Saccharomyces cerevisiae) supplementation on rumen fermentation and metabolic profile of dairy cows in early lactation. J Anim Physiol Anim Nutr. 2019;103:447-55. https://doi.org/10.1111/ jpn.13048

31. Burdick Sanchez NC, Broadway PR, Carroll JA. Influence of yeast products on modulating metabolism and immunity in cattle and swine. Animals. 2021;11:371. https://doi.org/10.3390/ ani11020371

32. Oetzel GR. Herd-level ketosis-diagnosis and risk factors. Poster session presented at: Preconference Seminar 7C: Dairy Herd Problem Investigation Strategies: Transition Cow Troubleshooting American Association of Bovine Practitioners 40th Annual Conferenc; 2007; Sep 19; Vancouver, BC. p. 67-99. 